\title{
FORMAÇÃO CONTINUADA EM UMA ESCOLA MUNICIPAL DE CAMPO GRANDE-MS (2017-2019): UM ESPAÇO DE APRENDIZAGEM COLETIVA
}

\author{
Patricia Florencio da Silva Cardoso ${ }^{1}$, lara Augusta da Silva ${ }^{2}$, Vanessa da Silva Rubinho ${ }^{3}$ \\ ${ }^{1}$ Pós-graduada em Educação Infantil, Psicopedagogia e Coordenação Pedagógica - Universidade Federal de Mato \\ Grosso do Sul - UFMS. Diretora Adjunta da Escola Municipal Prof. Licurgo de Oliveira Bastos, MS. ORCID iD: \\ https://orcid.org/0000-0003-0221-9041 E-mail: patriciafscardoso@gmail.com \\ ${ }^{2}$ Doutora em Educação pela Universidade Federal de Mato Grosso do Sul - UFMS. Docente Sênior do Programa de \\ Pós-Graduação Stricto Sensu - Mestrado Profissional em Educação, da Universidade Estadual de Mato Grosso do Sul - \\ UEMS, Campo Grande, MS. ORCID iD: https://orcid.org/0000-0001-8202-6965 E-mail: iara2ufms@gmail.com \\ ${ }^{3}$ Especialista em Ensino da Língua Espanhola no Brasil - Universidade Cândido Mendes. Professora Formadora de \\ Linguagens e suas tecnologias na Coordenadoria Regional de Educação (CRE-2) - Secretaria de Estado de Mato Grosso \\ do Sul, MS. ORCID iD: https://orcid.org/0000-0003-2886-7979 E-mail: prof.vanessarubinho@gmail.com
}

\section{RESUMO}

$\mathrm{O}$ artigo tem como finalidade discutir a formação continuada de professores, tendo como base a observação de ações desenvolvidas por uma Escola Municipal de Campo Grande-MS, no período de 2017 a 2019. O estudo aborda questões relacionadas à formação continuada de professores, ressalta a importância de se assegurar um tempo/espaço escolar para reflexões que visem ao aprofundamento das concepções teórico-filosóficas e metodológicas subjacentes ao Projeto Político Pedagógico. Enfatiza-se a importância do espaço escolar como lócus de formação dos professores, a fim de que estes adquiram maior consciência das suas ações, ampliem o seu nível de reflexão e análise, e, dessa forma, contribuam para a melhoria da práxis pedagógica. Trata-se, portanto, de uma pesquisa de observação, descritiva, de abordagem qualitativa, cujo objetivo foi evidenciar a importância da formação continuada promovida em uma escola da rede municipal de Campo Grande-MS. A metodologia incluiu a consulta e análise de fontes documentais da escola e de normas legais. Como aporte teórico utilizaram-se autores como Alves (2005, 2006, 2008), Nóvoa (2012), Magalhães e Azevedo (2015), que, de modo geral, consideram a formação continuada como fundamental no processo de construção de conhecimento do professor, com vistas ao aperfeiçoamento do trabalho pedagógico. Evidenciou-se que a escola em referência segue o princípio fundamental do trabalho coletivo, tendo em vista que procura envolver a coordenação pedagógica, a direção escolar e o grupo de professores, com o propósito de promover a ampliação do conhecimento de seus docentes.

Palavras-chave: Formação continuada; Espaço escolar; Trabalho docente.

\section{CONTINUING TRAINING IN A MUNICIPAL SCHOOL IN CAMPO GRANDE- MS (2017-2019): A COLLECTIVE LEARNING SPACE}

\section{ABSTRACT}

The article aims to discuss the continuing education of teachers, based on the observation of actions developed by a Municipal School of Campo Grande-MS, in the period from 2017 to 2019. The study addresses issues related to the continuing education of teachers, emphasizes the importance of ensuring a time/school space for reflections aimed at deepening the theoretical-philosophical and methodological conceptions underlying the Political Pedagogical Project. The importance of the school space as a locus of teacher training is emphasized, in order for them to acquire greater awareness of their actions, expand their level of reflection and analysis, and thus contribute to the improvement of pedagogical praxis. It is, therefore, a descriptive observation research, with a qualitative approach, whose objective was to highlight the importance of continuing education promoted in a school of the municipal network of Campo GrandeMS. The methodology included consultation and analysis of school documentary sources and legal standards. As theoretical contribution, authors such as Alves $(2005,2006,2008)$, Nóvoa (2012), Magalhães 
and Azevedo (2015), who generally consider continuing education as fundamental in the process of building teacher knowledge, with a view to improving pedagogical work. It was evidenced that the school in reference follows the fundamental principle of collective work, considering that it seeks to involve pedagogical coordination, school management and the group of teachers, with the purpose of promoting the expansion of the knowledge of its teachers.

Keywords: Continuing education; School space; Teaching work.

\section{EDUCACIÓN CONTINUA EN UNA ESCUELA MUNICIPAL DE CAMPO GRANDE-MS (2017-2019): UN ESPACIO DE APRENDIZAJE COLECTIVO}

\section{RESUMEN}

El artículo tiene como objetivo discutir la formación continua de docentes, a partir de la observación de acciones desarrolladas por una Escuela Municipal de Campo Grande-MS, en el período de 2017 a 2019. EI estudio aborda temas relacionados con la formación continua de docentes, enfatiza la importancia de asegurar un tiempo / espacio escolar para las reflexiones encaminadas a profundizar los conceptos teóricofilosóficos y metodológicos subyacentes al Proyecto Político Pedagógico. Se enfatiza la importancia del espacio escolar como locus de formación docente, para que adquieran una mayor conciencia de sus acciones, amplíen su nivel de reflexión y análisis, y contribuyan así a la mejora de la praxis pedagógica. Se trata, por tanto, de una investigación observacional, descriptiva, con enfoque cualitativo, cuyo objetivo fue resaltar la importancia de la educación continua promovida en una escuela de la red municipal de Campo Grande-MS. La metodología incluyó la consulta y el análisis de fuentes documentales escolares y normas legales. Como soporte teórico se utilizaron autores como Alves (2005, 2006, 2008), Nóvoa (2012), Magalhães y Azevedo (2015), quienes, en general, consideran la educación continua como fundamental en el proceso de construcción del conocimiento del docente, con miras a mejorar el trabajo pedagógico. Se evidenció que la escuela en cuestión sigue el principio fundamental del trabajo colectivo, en vista de que busca involucrar la coordinación pedagógica, la gestión escolar y el grupo de docentes, con el propósito de promover la expansión del conocimiento de sus docentes.

Palabras clave: Educación continua; Espacio escolar; Trabajo docente.

\section{INTRODUÇÃO}

Formação de professores é um assunto amplamente abordado nos debates sobre educação. Existe um grande número de produções acadêmicas como artigos, dissertações, teses, além de livros que tratam sobre a temática. Verificam-se, inclusive, linhas de pesquisas voltadas ao tema nos cursos de pósgraduação da área de educação, com a dedicação de muitos pesquisadores cujo propósito é contribuir para o aperfeiçoamento do trabalho docente na educação básica. Tomou-se, como pressuposto para compreender a formação continuada, que educação é um fenômeno social, portanto, é produto das necessidades características de determinados momentos históricos.

A questão da formação docente foi colocada em relevo, no Brasil, a partir na década de 1990, devido a três fatores principais: a instituição da Lei de Diretrizes e Bases da Educação Nacional no 9.394, de 1996; as reformas educacionais promovidas pelo Estado e a chamada "reestruturação produtiva" da sociedade capitalista. A LDBEN - Lei Darcy Ribeiro -, sancionada pelo então Presidente da República Fernando Henrique Cardoso, em 1996, é referida como um marco para o vigor que o tema formação do professor assumiu no cenário brasileiro, nos anos 1990. A LDBEN de 1996, como se sabe, no bojo das reformas propostas para a educação em geral, traz os artigos 61 a 65 do Título VI - Dos Profissionais da Educação -, que tratam de forma detalhada sobre a formação inicial e a formação continuada, no sentido de introduzir mudanças que atendessem às novas configurações das políticas públicas educacionais gerenciadas pelo Estado de perfil neoliberal.

Reformas foram impostas ao sistema de ensino brasileiro por determinação, muitas vezes, dos organismos internacionais (Banco Mundial, Fundo Monetário Internacional, UNESCO), os quais buscavam introduzir ideias e estratégias que visavam uma adequação da formação dos profissionais da educação às demandas do mercado de trabalho em consonância com as 
exigências da transformação pela qual a organização da sociedade capitalista vinha passando, desde o final da década de 1970, aprofundada ao longo dos anos 1990. A mudança que ocorria na sociedade capitalista nas últimas décadas do século XX foi intitulada, por muitos autores que estudam essa questão, de "reestruturação produtiva". Tratava-se de uma mudança estrutural no sistema econômico causada pela introdução constante e intensa, em escalas crescentes de novas tecnologias ao processo de produção. Com ela, a forma de organização do trabalho fora mudada.

No Brasil, a formação de professores, em especial a denominada continuada, além de estar inserida nos estudos acadêmicos, está presente nas políticas públicas de educação do Ministério da Educação (MEC) e de outros órgãos das esferas estadual e municipal, como também na escola. Em Campo Grande, capital do estado de Mato Grosso do Sul, observa-se uma preocupação em relação ao tema, da Secretaria Municipal de Educação (SEMED), quando publicou normas legais de sistematização da formação continuada de seus docentes, a exemplo da Resolução no 200, de 2019, que institui esse sistema no âmbito da própria SEMED e das escolas da sua rede de ensino. Essa Resolução criou um Programa de Formação Continuada que foi desenvolvido paralelamente ao de cada escola da rede municipal de Campo Grande-MS.

É nesse contexto que se desenvolveu uma pesquisa cujo objetivo foi evidenciar a importância da formação continuada promovida em uma escola da rede municipal de Campo Grande - MS. A questão motivadora e direcionadora do estudo era, então, "Qual a relevância de um programa de formação continuada dos professores, no âmbito local e global, de uma escola municipal em Campo Grande, MS?".

Desse modo, mediante a política de formação continuada proposta pelas universidades, pelas instituições de educação (MEC, SED/MS, SEMED/CG), resolveu-se escolher uma escola da rede municipal de Campo Grande, Mato Grosso do Sul, para realizar um estudo sobre a formação continuada de professores. Essa escola havia elaborado um plano abrangente de formação continuada que pretendia incluir todos os profissionais envolvidos com a execução do trabalho pedagógico, com propósitos e estratégias a fim de contribuir para o aperfeiçoamento do trabalho docente e, como consequência, a melhorar o processo de ensino e de aprendizagem dos estudantes.

Este artigo não se propõe fazer o relato dessa experiência, mas demonstrar a importância dela, tanto para o contexto local quanto para o global, tendo como suporte a observação das ações que constituíram um plano de formação continuada, nessa escola municipal, durante o período de 2017 a 2019, destinado a professores da educação infantil e do ensino fundamental. 0 plano envolveu, também, os coordenadores pedagógicos e o diretor escolar, com o propósito de incluir todos os profissionais da instituição escolar, a partir de uma organização bem delineada e sistematizada com utilização de instrumentos criteriosamente elaborados.

Ressalta-se, aqui, a relevância dos encontros, das discussões e dos estudos realizados durante a formação continuada, que objetivava a reflexão e o replanejamento das ações realizadas pelos profissionais da escola. A prioridade era o aperfeiçoamento das atividades de formação continuada e, consequentemente, a efetivação de um trabalho coletivo abrangente que promovesse mudanças concretas na organização do trabalho didático no âmbito do espaço escolar.

Com o propósito de fundamentar teoricamente as ideias e as reflexões a respeito da formação continuada de professores da educação básica nos tempos atuais, realizou-se uma revisão documental e bibliográfica, em documentos oficiais e institucionais, bem como em produções acadêmicas.

O artigo está estruturado nas seguintes seções: introdução, delineamento metodológico, resultado e discussão e conclusão.

\section{DELINEAMENTO METODOLÓGICO}

Para desenvolver este estudo sobre formação continuada de professores e evidenciar a importância dessa formação, utilizou-se como procedimento metodológico principal, a observação das ações desenvolvidas em uma Escola Municipal de Campo Grande-MS. Conquanto já ocorressem, anteriormente, na escola, ações de formação continuada, no período de 2017 a 2019 a direção escolar, os coordenadores pedagógicos e os professores decidiram, em conjunto, sistematizar o processo de formação por meio da elaboração de instrumentos, de realização de encontros para estudos, para os quais utilizaram tecnologias 
digitais, livros, documentos oficiais nacionais e locais que são considerados fundamentais para conduzir ações formativas na instituição escolar.

Outro procedimento utilizado foi o estudo de documentos e normas legais produzidos por instituições como o Mistério de Educação (MEC), a Secretaria Municipal de Educação (SEMED) de Campo Grande-MS e os da própria escola que foi o lócus da pesquisa; destacam-se a Lei de Diretrizes e Bases da Educação Nacional (LDBN) 9.394/1.996, as Diretrizes Curriculares Nacionais da Educação Básica (2013), a Resolução № 200, de 21 de novembro de 2019, o Projeto Político Pedagógico da escola em referência (2016) e o respectivo Regimento Escolar (2019).

Além do estudo de fontes documentais, buscou-se sustentação teórica em alguns autores: Alves (2008, 2006, 2005), Nóvoa (2012), Magalhães e Azevedo (2015), Rebolo et al. (2012), com o propósito de abordar a formação continuada como uma ação da escola, que agrega outras atividades pertinentes às funções da escola pública contemporânea, no sentido de contribuir para atender às demandas da sociedade. Dessa maneira, a formação continuada foi estudada, considerando como a escola está constituída na atualidade, a organização do trabalho didático e o professor que desempenha junto com os alunos a relação educativa (ALVES, 2008, p. 103).

Considera-se pertinente, neste estudo sobre a formação continuada promovida na escola municipal lócus da investigação, uma breve contextualização dessa instituição. Localizada na Região Urbana Segredo, na cidade de Campo Grande, capital do estado de Mato Grosso do Sul; foi criada no ano de 1980. Atualmente, atende em média, 1.900 alunos da educação infantil e do ensino fundamental. Os estudantes, em sua maioria, são oriundos de famílias em situação de vulnerabilidade. Trata-se de crianças e jovens cujas famílias dependem da ação social do Estado (uniforme, kit de material escolar, Bolsa Família, Vale Renda, LOAS e outros) para manter-se economicamente. Muitas famílias têm de três a cinco filhos e, algumas, chegam a ter seis. A escola é considerada uma referência devido a excelência dos serviços educacionais prestados ao município ${ }^{1}$. Atualmente a instituição

\footnotetext{
${ }^{1}$ Acrescenta-se, a esse fato, a grande procura por matrícula na escola, muitas vezes com lista de espera e o fato de ex-alunos matricularem seus filhos e netos na instituição escolar, mesmo não sendo a escola próxima da sua residência. Observe-se, também, que
}

tem 103 professores, 10 apoios pedagógicos especializados (APEs) e 13 assistentes educacionais inclusivos (AEls).

Apresenta-se, a seguir, 0 desenvolvimento do estudo sobre a formação continuada de professores, tendo como base a observação desenvolvida nessa escola municipal.

\section{RESULTADOS E DISCUSSÃO}

Não há como refletir e pensar sobre educação de qualidade sem passar pela formação continuada de professores, haja vista que juntamente com a formação inicial, essa tem sido considerada uma questão fundamental nas políticas públicas para a educação. A escola desempenha, hoje, novos e variados papéis. Tem se constituído em um espaço de constante mutação, no qual o professor tem um papel primordial, uma vez que é responsável pela mudança de atitude e pensamento dos alunos. Desse modo, esse docente precisa estar preparado para os novos e crescentes desafios desta geração que, como nunca, na história da humanidade, tem contato com tecnologias e fontes de acesso ao conhecimento.

Um grande número de estudiosos tem apontado a formação continuada como alternativa para melhorar a prática docente. Cunha e Krasilchik (2000) observam que essa formação não se esgota em um curso de atualização, mas deve constituir um processo que precisa ser construído constante e continuamente no cotidiano escolar.

A formação continuada de professores no Brasil está prevista em leis, pareceres, resoluções, de forma a torná-la uma política pública que deve ser executada pelo Ministério da Educação, pelas Secretarias Estaduais de Educação e pelas Secretarias Municipais de Educação. Assim é que a Secretaria Municipal de Educação (SEMED) de Campo Grande há algum tempo, tem desenvolvido programas de formação continuada junto às escolas da rede municipal.

As escolas, como instituições vinculadas ao sistema de educação nacional, também procuram desenvolver projetos e programas que atendam às orientações legais voltadas para a formação continuada de seus docentes. Tal realidade propiciou que se investigasse sobre as ações que, nesse sentido, uma escola municipal

muitos profissionais - professores e diretores - que trabalham na escola foram ex-alunos. 
de Campo Grande, Mato Grosso do Sul, tem realizado, observando-se o período de 2017 a 2019.

Conquanto a escola em referência tivesse desenvolvido ações para a formação continuada de seus docentes, nos documentos oficiais da escola - Projeto Político Pedagógico (PPP), Regimento Escolar, Plano de Melhoria da Escola (PME), Plano de Ação da Coordenação Pedagógica - não constavam propostas estruturadas que respaldassem a sua execução de maneira mais efetiva. Esses documentos fazem referência à formação continuada, porém, não detalham formas de organização, a exemplo de um plano de trabalho que envolvesse os professores, os coordenadores pedagógicos e o diretor escolar ${ }^{2}$. Não se observou a existência de diretrizes bem definidas que sistematizassem todas as etapas e procedimentos que envolvem a formação continuada de professores, um aspecto que atinge o cerne da organização do trabalho didático na escola. De acordo com Alves, a organização do trabalho didático envolve três aspectos:

$$
\begin{aligned}
& \text { a) ela é, sempre, uma } \\
& \text { relação educativa que } \\
& \text { coloca, frente a frente, } \\
& \text { uma forma histórica de } \\
& \text { educador, de um lado, e } \\
& \text { uma forma histórica de } \\
& \text { educando (s), de outro; b) } \\
& \text { realiza-se com a mediação } \\
& \text { de recursos didáticos, } \\
& \text { envolvendo os } \\
& \text { procedimentos técnico- } \\
& \text { pedagógicos do educador, } \\
& \text { as tecnologias } \\
& \text { educacionais pertinentes e } \\
& \text { os conteúdos } \\
& \text { programados para servir } \\
& \text { ao processo de } \\
& \text { transmissão do } \\
& \text { conhecimento; c) e implica } \\
& \text { um espaço físico com } \\
& \text { características peculiares, } \\
& \text { onde ocorre (ALVES, 2005, } \\
& \text { p. 10-11). }
\end{aligned}
$$

A formação continuada de professores deve favorecer a reflexão sobre o trabalho educativo, as funções da escola pública, o uso de metodologias de ensino diferenciadas, a

\footnotetext{
${ }^{2}$ Segundo o Regimento Escolar (CAMPO GRANDE, 2019, p. 37), a direção escolar é composta por diretor e diretor adjunto, eleitos pela comunidade escolar e nomeados por ato próprio do chefe do executivo.
}

exploração de ambientes virtuais e tecnologias, o conhecimento sobre a área de atuação e da educação de modo geral, entre outros. Nessa linha de raciocínio, Teixeira (2012), apoiada em Ferry (2008), afirma que a formação continuada precisa estar relacionada à realidade na qual está inserida.

Para que a formação ocorra, algumas condições são necessárias, conforme aponta Ferry (2008): lugar, tempo e relação com a realidade. Tais condições estão imbricadas na medida em que só há formação se for possível refletir sobre a experiência que se estabelece no contato com a realidade, a qual está condicionada ao tempo e ao espaço para tanto. O autor chama atenção, no entanto, para o fato de que o contato com a realidade não se restringe ao sentido concreto, mas ocorre, sobretudo, no sentido representacional, ou seja, é necessário antecipar situações reais a serem enfrentadas e planejar as formas apropriadas de trabalhar com elas. Isso caracteriza o momento de preparação da formação. Sendo assim, o que se passa na formação é que há necessidade de representar a realidade para atuar nela (TEIXEIRA, 2012, p. 116-117).

Ainda que a SEMED de Campo Grande realizasse ações de formação em outros espaços, com estratégias e objetivos diferenciados, a escola que serviu de base para o presente estudo, diante da necessidade de sistematizar a formação continuada de seus professores, levou a efeito um programa de formação in loco, considerando a importância da parceria entre a direção escolar e os coordenadores pedagógicos, uma vez que entre as atribuições desses profissionais está a da participação e acompanhamento da formação dos professores.

Nesse sentido, Rosa e Schnetzler (2003, p. 28) defendem que "para romper com a 
racionalidade técnica, uma possibilidade é a ideia de parceria colaborativa. Nesta parceria colaborativa, a partir da interação entre pares que assumem papéis específicos no processo, a reflexão e a intervenção na realidade se viabilizam".

Atas, fotos, ambiente virtual comprovam, na escola lócus da investigação, as ações de formação continuada realizadas nos anos de 2017 a 2019, registros que têm facilitado a avaliação de processos para o replanejamento das ações.

Por meio da observação que se fez sobre a formação continuada nessa escola, foi possível identificar a realização de encontros bimestrais dentro da própria instituição. Esses encontros eram marcados por dois momentos distintos. 0 primeiro destinava-se a discussões e estudos de assuntos voltados à gestão escolar, à organização da escola e, também, às atribuições de cada profissional que trabalha na escola. O segundo momento era dedicado à ampliação dos estudos com o propósito de fazer circular o conhecimento, por meio de estudos de livros e de discussões sobre temáticas relacionadas à educação básica.

As metodologias eram diversificadas, desde atividades orientadas individualmente até a participação coletiva em palestras, discussões de temas sobre as estratégias para a recuperação paralela, ações para incentivar a maior participação da família na escola, entre outras. Durante os encontros de formações, os profissionais responsáveis disponibilizavam instrumentos existentes na escola, tais como: livros técnicos, jogos, atividades diagnósticas, aulas e avaliações virtuais, e organização de eventos com exposição de trabalhos dos alunos. Observou-se que todas as atividades desenvolvidas durante os encontros estavam em consonância com o Projeto Político Pedagógico (PPP). A escola tinha como objetivo principal, ao realizar a formação continuada dos professores, o aprimoramento da função docente, de modo que a maioria dos alunos conseguisse aprender o que era proposto no currículo para o ano escolar.

No espaço escolar, como se sabe, atuam outros profissionais, que auxiliam para que $o$ processo de formação do aluno seja efetivado. Cada profissional ocupa um cargo com atribuições específicas, conforme estabelece o Regimento Escolar (2019) e o Projeto Político

\footnotetext{
3 De acordo com o documento publicado pelo MEC em 2013, “O regimento escolar trata da natureza e da finalidade da instituição;
}

Pedagógico (2016), os quais têm o propósito de normatizar a organização e o funcionamento da escola. Esses profissionais, ao desenvolverem suas funções de modo satisfatório contribuem para o aperfeiçoamento do processo de ensino e aprendizagem dos alunos.

Vários documentos oficiais, nacionais e institucionais, têm servido de fundamento às ações de formação continuada na escola em referência neste estudo: a) a Lei de Diretrizes e Bases da Educação Nacional no 9.394 de 1996; b) o Projeto Político Pedagógico de 2016; c) o Regimento Escolar de 2019; d) a Resolução SEMED/Campo Grande-MS no 200, de 21 de novembro de 2019, que dispõe sobre a organização do ano escolar e ano letivo para o exercício de 2020, nas escolas da Rede Municipal de Ensino; e) as Comunicações Internas (Cls) expedidas pela SEMED/CG/MS, como por exemplo, a que trata da organização bimestral do programa formativo denominado "Reflexões Pedagógicas: Diálogos entre a teoria e a prática", sob a responsabilidade da Superintendência de Gestão das Políticas Educacionais/SUPED da Secretaria Municipal de Educação/SEMED/CG.

Tendo como base esses documentos e as legislações que regulamentam a educação em âmbitos nacional e local, a escola elaborou e executou o Cronograma Anual de Formação de Professores referente aos anos de 2017, 2018 e 2019. Os cronogramas têm a mesma sequência de etapas tais como: a) data e responsável da formação, b) os temas a serem estudados por ordem de interesse, c) metodologias diferenciadas por meio de palestra com professores das universidades, apresentação de experiências exitosas dos professores, leitura e estudo de livros técnicos e teóricos. Desse modo, foram estabelecidos objetivos pedagógicos a serem atingidos durante $o$ ano letivo pelos professores das diferentes etapas de ensino.

Observou-se que a escola valoriza fortemente a participação da direção escolar, no processo de formação continuada dos professores. Hengemühle (2007, p. 191) respalda essa iniciativa, uma vez que sugere que, embora

\footnotetext{
da relação da gestão democrática com os órgãos colegiados; das atribuições de seus órgãos e sujeitos; das suas normas pedagógicas, incluindo os critérios de acesso, promoção e a mobilidade escolar; e dos direitos e deveres dos seus sujeitos: estudantes, professores, técnicos, funcionários, gestores, famílias, representação estudantil e função das suas instâncias colegiadas" (BRASIL, 2013, p. 51).

4 Tanto o Projeto Político Pedagógico como o Regimento Escolar são documentos do acervo da Escola Municipal de Campo Grande-MS, lócus de observação neste estudo sobre formação continuada.
} 
a direção escolar não seja responsável diretamente pela formação continuada, é importante que ela colabore ou analise essa atividade em conjunto com a coordenação pedagógica. Desse modo, diretor escolar e coordenador pedagógico entendem que a organização da formação continuada não deve ser planejada individualmente, mas que deve ser um resultado de trabalho coletivo a partir da análise de diversos pontos de vista, tais como das dificuldades encontradas pelos professores, coordenador pedagógico e direção escolar e os aspectos a serem aperfeiçoados na escola. 0 envolvimento da direção escolar acontece em consonância com a equipe técnico-pedagógica ${ }^{5}$, uma vez que são participantes do processo basilar de formação continuada dos professores para melhorar a educação oferecida pela escola.

Nas escolas públicas da Rede Municipal de Campo Grande - MS, o Calendário Escolar ${ }^{6}$ anual é elaborado com base nas orientações da Coordenadoria de Normatização das Políticas Educacionais/CONOPE da Superintendência de Gestão e Normas/SUGENOR da SEMED, por meio da Resolução SEMED no 200, de 21 de novembro de 2019. Esse documento dispõe sobre a organização do ano escolar de 2020, como também estabelece a organização dos dias destinados às formações destinados à SEMED e os destinados para a escola. Nesse sentido, a escola utiliza essa legislação como norma para elaborar o calendário escolar e as formações continuadas.

De posse dos documentos oficiais, elabora-se um esboço do calendário escolar com possíveis datas que não foram determinadas pela SEMED. Desse modo, após aprovado pelos professores e pelo inspetor escolar, utiliza-se como base para elaborar e executar o Cronograma Anual de Formação de Professores. A Resolução no 200, já mencionada, estabelece, para o ano letivo de 2020, oito encontros de formação continuada, sendo quatro realizados pela escola e quatro pela SEMED, em espaços e com temáticas determinados por essa instituição. Nas Resoluções dos anos anteriores, observou-se

\footnotetext{
${ }^{5}$ São profissionais como coordenador pedagógico que realizaram o processo seletivo; o apoio pedagógico, os quais são encaminhados pela Secretaria Municipal de Educação de Campo Grande/MS; o orientador educacional ou supervisor escolar, ambos oriundos de concurso público.

${ }^{6} \mathrm{O}$ calendário escolar é o instrumento que expressa à ordenação temporal das atividades desenvolvidas ao longo do ano pelas unidades escolares doa rede municipal.
}

que um número maior de encontros foi destinado para a formação continuada de professores. Pode-se inferir, nesse contexto, que as políticas de formação continuada não tenham, ainda, finalidades bem definidas em âmbitos nacional e local, tendo em vista que essas políticas ficam dependentes do direcionamento dado pelo grupo de gestores que assume a execução dos programas e projetos de formação continuada destinados aos profissionais da educação.

A formação continuada está normatizada não apenas na legislação local, mas também em âmbito nacional, a exemplo da Resolução CNE/CEB no 04, de 13 julho de 2010, que estabeleceu as Diretrizes Curriculares Nacionais Gerais para a Educação Básica, a qual define as diretrizes gerais para a Educação Básica e, no que tange à formação inicial e continuada dos profissionais da educação, descreve os vários aspectos referentes ao tema, conforme o Capítulo IV - O professor e a formação inicial e continuada, Artigos 56 e 57, parágrafos 10 e 20 :

Art. 56. A tarefa de cuidar e educar, que a fundamentação da ação docente e os programas de formação inicial e continuada dos profissionais da educação instauram, reflete-se na eleição de um ou outro método de aprendizagem, a partir do qual é determinado o perfil de docente para a Educação Básica, em atendimento às dimensões técnicas, políticas, éticas e estéticas. $\S$ 10 Para a formação inicial e continuada, as escolas de formação dos profissionais da educação, sejam gestores, professores ou especialistas, deverão incluir em seus currículos e programas:

a) o conhecimento da escola como organização complexa que tem a função de promover a educação para e na cidadania;

b) a pesquisa, a análise e a aplicação dos resultados de investigações de 
interesse da área educacional;

c) a participação na gestão de processos educativos e na organização e funcionamento de sistemas e instituições de ensino;

d) a temática da gestão democrática, dando ênfase à construção do projeto políticopedagógico, mediante trabalho coletivo de que todos os que compõem a comunidade escolar são responsáveis.

Art. 57. Entre os principais definidos para a educação nacional está a valorização do profissional da educação, com a compreensão de que valorizá-lo é valorizar a escola, com qualidade gestorial, educativa, social, cultural, ética, estética, ambiental.

$\S$ 2ㅇ Os programas de formação inicial e continuada dos profissionais da educação, vinculados às orientações destas Diretrizes, devem prepará-los para o desempenho de suas atribuições, considerando necessário:

a) além de um conjunto de habilidades cognitivas, saber pesquisar, orientar, avaliar e elaborar propostas, isto é, interpretar e reconstruir o conhecimento

coletivamente;

b) trabalhar cooperativamente em equipe;

c) compreender, interpretar e aplicar a linguagem e os instrumentos produzidos ao longo da evolução tecnológica, econômica e organizativa;

d) desenvolver competências para integração com a comunidade e para relacionamento com as famílias (BRASIL, 2013, p. 78-79).

Essa Resolução preconiza que a formação inicial e continuada é imprescindível no espaço escolar, pautada no princípio de uma gestão democrática e compromissada com a qualidade da educação. Portanto, a formação é abrangente e não se restringe apenas a um aspecto das atribuições dos docentes, mas a todo o complexo processo que envolve o ensino escolar. Assim, a formação continuada visa contribuir para a sistematização de conhecimentos que não se esgotam após um período específico de estudo, mas estando presente durante toda a vida profissional do docente.

A LDBEN no 9.394, de 24 de dezembro de 1996, também trata da formação dos profissionais da educação, no Título VI - Dos Profissionais da Educação, Artigo 61:

Art. 61. Parágrafo único: A formação dos profissionais da educação, de modo a atender às especificidades do exercício de suas atividades, bem como aos objetivos das diferentes etapas e modalidades da educação básica, terá como fundamentos:

I - a presença de sólida formação básica, que propicie o conhecimento dos fundamentos científicos e sociais de suas competências de trabalho;

II - a associação entre teorias e práticas, mediante estágios supervisionados e capacitação em serviço (BRASIL, 2017).

Esse Artigo da LDBN/1996 destaca que a formação dos profissionais da educação deve priorizar dois aspectos principais: a formação básica que favoreça o conhecimento dos fundamentos científicos e sociais relacionados ao trabalho docente e a relação entre teoria e prática no campo da educação.

Mais recentemente, o Plano Nacional de Educação (PNE) instituído pela Lei no 13.005, de 25 de junho de 2014 também destaca, entre as 
suas metas e estratégias, a necessidade de se promover a formação inicial e a formação continuada dos profissionais da educação. No que se refere, especificamente, à formação continuada dos profissionais da educação, o PNE de 2014 determina, na meta 16 e na estratégia 16.1 o seguinte:

Meta 16: formar, em nível de pós-graduação, $50 \%$ (cinquenta por cento) dos professores da educação básica, até o último ano de vigência deste PNE, e garantir a todos (as) os (as) profissionais da educação básica formação continuada em sua área de atuação, considerando as necessidades, demandas e contextualizações dos sistemas de ensino.

Estratégia 16.1: realizar, em regime de colaboração, o planejamento estratégico para dimensionamento da demanda por formação continuada e fomentar a respectiva oferta por parte das instituições públicas de educação superior, de forma orgânica e articulada às políticas de formação dos Estados, do Distrito Federal e dos Municípios (BRASIL, 2014, p. 55).

De acordo com as legislações já referidas aqui, percebe-se que a formação continuada é entendida como fundamental para o exercício do magistério, pois objetiva "[...] possibilitar ao docente à aquisição de conhecimentos e atualização de práticas próprias da profissão, tornando-os educadores mais preparados a atender às exigências impostas pela sociedade contemporânea [...]" (SILVA; VARGAS, 2016, p. 167).

Desse modo, a formação continuada na instituição escolar é vista como relevante para melhorar o processo de ensino e de aprendizagem dos alunos, bem como proporcionar um ambiente de trabalho cooperativo, despertando a coletividade, a parceria, a troca de experiências e os conhecimentos entre profissionais envolvidos.
Alguns questionamentos têm servido de direcionamento para o desenvolvimento da formação continuada na escola municipal de Campo Grande-MS lócus da investigação que aqui se tem descrito: Quem é o responsável pela organização da formação continuada na escola? Com que periodicidade deve ocorrer? Que temas podem ser abordados? Que livros e documentos serão selecionados para leitura? Quais questões administrativas precisam ser tratadas nesses momentos? Qual o tempo necessário de planejamento da formação continuada? As respostas a essas questões têm sido trabalhadas pela escola por meio de discussões e estudos de materiais teóricos e documentais providenciados pela direção escolar e pela coordenação pedagógica, no processo de organização da formação continuada dos professores, ao longo do período compreendido entre os anos de 2017 a 2019.

É utópico, entretanto, considerar que a formação continuada resolve todos os problemas da educação ou da escola. Sabe-se que a instituição escolar está inserida em um contexto social que envolve questões de ordem econômica e política, o que extrapola as atividades de formação continuada de professores desenvolvida pela escola. A valorização dos profissionais, o investimento na estrutura física das escolas, a formação inicial e continuada, a garantia de ensino público e de qualidade dependem de ações de órgãos federais, estaduais e municipais por meio de políticas públicas de educação. Mesmo a formação continuada de professores que acontece de forma organizada pela escola não resolverá todos os problemas que permeiam o seu funcionamento.

Os profissionais da Escola Municipal de Campo Grande-MS observada consideram que a formação continuada constitui uma oportunidade de reflexão, por meio da qual os professores podem avançar nos estudos e no aprimoramento de conhecimentos, ampliando a discussão pedagógica de modo a não mais procurar "culpados" para o fracasso do aluno.

Na dinâmica das atividades desenvolvidas pela escola, dificilmente 0 coordenador pedagógico consegue realizar, de forma efetiva, a formação continuada, devido às inúmeras atribuições desse profissional. Desse modo, muitas vezes essa atividade não passa de um serviço burocrático, realizado para cumprir a solicitação da SEMED de Campo Grande-MS ou o Calendário Escolar. No período de 2017 a 2019, a 
escola em referência, neste estudo, elaborou cronogramas anuais de formação de professores com o propósito de sistematizar o trabalho executado pela direção escolar em articulação com os coordenadores pedagógicos, tendo como base dados concretos.

Assim, a escola criou instrumentos e estratégias para normatizar, organizar e avaliar as atividades de formação, com a participação de todos os profissionais nas etapas de elaboração, de execução e de avaliação, de forma a atender às demandas evidentes no processo de formação continuada do grupo.

Para elaborar o programa anual dessa formação continuada, a escola utiliza informações coletadas por meio do acompanhamento das atividades pedagógicas e da organização da rotina dos alunos no espaço escolar, estudos teóricos, análise das aulas ministradas pelos professores, observação dos cadernos dos alunos e devolutiva aos pais e discentes durante $o$ ano letivo.

No mês de dezembro de cada ano, antes do término do ano letivo, os professores e coordenadores pedagógicos respondem a um questionário que provê informações necessárias à organização da formação continuada. Nesse questionário constam, além de sugestões de temas para o ano seguinte, uma análise dos encontros, a avaliação da metodologia, o tempo de duração, as leituras prévias e proposições e quais formações foram relevantes para a prática pedagógica. Para a escola, a devolutiva das avaliações feitas pelos professores e pelos coordenadores pedagógicos sobre a formação continuada tem sido satisfatória. O compromisso em responder o questionário tem sido fundamental para o aperfeiçoamento do processo de formação da instituição escolar, com vistas a apresentar informações que colaborem para o afeiçoamento do trabalho desenvolvido pelo professor na escola.

Inicialmente, a avaliação das formações continuadas nos anos de 2017 e 2018 ocorreu por meio da aplicação de um questionário no formato impresso. Para aperfeiçoar e viabilizar a tabulação dos dados do questionário, a partir de 2019 utilizaram-se recursos tecnológicos disponíveis na escola; esse instrumento de avaliação passou a ser disponibilizado no Formulário Google ${ }^{7}$. Os recursos tecnológicos

\footnotetext{
${ }^{7} \mathrm{O}$ formulário on-line tem as seguintes questões: 1- Com quais turmas você trabalha? 2- Você participou de todas as formações na escola? Se não, justifique sua resposta. 3- Tivemos momentos, com
}

fazem parte da dinâmica dessa escola e da vida dos homens, que fazem uso deles cotidianamente, utilizando celulares, smartphones, computadores e tablets.

A escola lócus da observação que aqui se descreve, tendo como referência a análise de todas as informações coletadas junto a todos profissionais envolvidos no processo educativo, elabora um Cronograma Anual de Formação de Professores, que atende os professores da educação infantil até 0 9o ano do ensino fundamental. O cronograma tem como pauta assuntos gerais - o Código de Ética dos servidores da rede municipal, o Projeto Político Pedagógico, o Regimento Escolar, a Avaliação Externa e Sistema Nacional de Avaliação da Educação Básica (SAEB), o Resultado dos índices de aproveitamento anual dos alunos e outros temas para atender solicitações da SEMED/CG. Ao longo do ano escolar, surgem assuntos específicos relacionados à educação infantil e ao ensino fundamental que necessitam ser estudados; desse modo, são acrescentados novos temas ao Cronograma Anual de Formação de Professores, procurando respeitar as peculiaridades de cada grupo de professores.

Esse cronograma, além de outros instrumentos, serve para organizar a formação continuada na escola. Não se trata de um documento rígido, pois tem como característica a inclusão de outros temas pertinentes, pautado nas necessidades de formação da realidade escolar.

Para desenvolver a formação continuada de professores, a escola utiliza outros instrumentos para a sistematização das ações executadas. Como estratégia para dinamizar a formação de professores no âmbito da unidade escolar são disponibilizados, na Plataforma Moodle $^{8}$, textos para leitura prévia, tarefas associadas ao estudo proposto, tais como elaboração de plano de aula com base na temática, resumo das ideias principais, ações

palestrantes, estudos e discussões. Quais destas formações foram mais significativas para você? 4- Essas formações auxiliaram na sua prática pedagógica e ou para aquisição de conhecimento pessoal? Explique de que maneira ocorreu. 5- No ano de 2020 pretendemos elaborar um plano de formação com o foco na leitura em todos os anos. Diante da organização para o próximo ano, quais temas você sugere para estudarmos? 6- De modo geral como você avalia as formações na escola em 2019? 7- Outras considerações que julgar necessárias.

${ }^{8} \mathrm{O}$ ambiente virtual Moodle é destinado a questões pedagógicas da escola, está organizando e permite acesso de qualquer local, para inserção de plano de aula, avaliações, acesso aos diários de classe, documentos oficiais da escola e Comunicação Interna da SEMEDCG/MS para consulta, dentre outros assuntos. 
para serem implementadas na escola e na prática docente, entre outras, ao término de cada formação realizada pelos professores, individualmente ou em grupo.

Para a implantação e a utilização do ambiente virtual Moodle, em janeiro de 2014 a direção escolar e a equipe técnico-pedagógica participaram de uma formação na SEMED$\mathrm{CG} / \mathrm{MS}$, antes do início do ano letivo. Ao tempo em que se desenvolveu a investigação por meio da observação, das 96 escolas da rede municipal de Campo Grande Mato Grosso do Sul, somente a escola municipal em questão utilizava o ambiente virtual Moodle. Cada membro da equipe técnicopedagógica criou seu espaço no ambiente virtual, que é organizado por meio de links como: Estudo, Avaliações, Atendimento Domiciliar, Planos de Aulas, entre outros. As salas virtuais com os alunos $^{9}$ foram iniciadas em 2015. Desde então, a cada início do ano letivo é solicitada, à SEMED, a abertura de uma nova sala para as atividades virtuais.

É oportuno que se ressalte a importância da utilização das tecnologias digitais como ferramentas na formação continuada de professores, coordenadores pedagógicos e direção escolar, com base no desenvolvimento de habilidades como acesso a ambientes virtuais, postagem de arquivos, seleção de site confiáveis, conhecimento e exploração de sites que auxiliam na compreensão de conteúdos, por parte dos alunos, que têm contato sistemático com os recursos tecnológicos.

A escola pública contemporânea acompanha as demandas atuais da sociedade capitalista, o que significa dizer que as instituições escolares sofrem influência da organização social de uma determinada época histórica. Portanto, os profissionais da educação devem ter clareza das funções que as tecnologias exercem na configuração do trabalho pedagógico. Nesse sentido, Alves (2006, p. 230) afirma que:

Mesmo a função
pedagógica, que tem sido
a sua razão de ser, deve
ser superada na
perspectiva de uma forma
histórica que atenda
necessidades
contemporâneas pela

${ }^{9}$ Criação de salas virtuais onde todos os professores de todas as disciplinas planejam aulas no Ambiente Moodle e os alunos realizam atividades na escola. incorporação de recursos tecnológicos de nossa época. Essa é a alternativa que lhe propiciará a possibilidade de incorporar conteúdos culturalmente significativos e, em decorrência, de ganhar relevância.

De acordo com esse autor, a função pedagógica é a razão da existência da escola moderna, contudo, ela precisa ser superada para atender às necessidades impostas pela sociedade atual. A intensificação da incorporação de recursos tecnológicos pela escola poderá incluir outros "conteúdos culturalmente significativos".

Diante do exposto, verifica-se que os recursos tecnológicos, juntamente com outros instrumentos, têm auxiliado na sistematização das formações continuadas desenvolvidas pela escola municipal estudada. Observa-se que, além do Cronograma Anual de Formação de Professores, a referida instituição escolar utiliza outros instrumentos considerados importantes para a execução da formação continuada, entre os quais se podem citar: Fichas de Organização da Reunião Pedagógica, Atas, Plataforma Moodle, Ficha de Avaliação dos Encontros de Formação.

Diversos autores têm considerado que a organização e a execução da formação continuada são precípuas no resultado do trabalho que o docente desenvolve no âmbito da escola. Enfatizam que a formação continuada deve ser efetivada de modo a envolver todos os profissionais, como o coordenador pedagógico, o diretor escolar e o próprio professor. Essa formação, na concepção de diversos pesquisadores, deve ser pautada na observação da prática educativa, na análise da aprendizagem dos discentes em sala de aula, no contexto em que os professores desempenham o trabalho pedagógico.

Moriconi (2017) faz referência a alguns desses autores - Garet et al. (2001), Snow-Renner e Lauer (2005), Yoon et al. (2007) e Blank e de Las Alas (2009) -, que, ao discutirem características de programas de formação continuada eficazes, mencionam a participação coletiva. Nesses estudos,

[...] geralmente a participação coletiva é tida como o contrário da participação individual, ou 
seja, trata-se de um grupo de professores de uma mesma escola, etapa de ensino, departamento/disciplina ou série que participam ativa e conjuntamente de uma experiência de formação continuada - em oposição a uma participação individual de professores em uma conferência ou workshop, por exemplo, (MORICONI, 2017, p. 30).

Sobre as vantagens dessa participação coletiva, Moriconi (2017, p. 31), com base em Garet et al. (2001), explicita:

[...] professores que trabalham em conjunto têm maiores chances de discutir conceitos, habilidades e problemas que surgem durante seu desenvolvimento

profissional; que são da mesma escola, departamento ou etapa de ensino conta com maiores oportunidades de compartilhar materiais curriculares, didáticos e demandas de avaliação; tendem a manter as mudanças na prática ao longo do tempo. [...] professores que dividem os mesmos estudantes podem discutir as necessidades desses estudantes durante as aulas.

Essa mesma autora faz referência a dois sentidos que têm sido atribuídos a essa formação continuada no espaço escolar com participação coletiva:

[...] por um lado, existe a ideia de que programas de formação continuada devem ser planejados a partir das necessidades específicas da escola - ou ao menos estarem alinhados com suas metas de melhoria - o que possibilita que os professores estejam presentes na identificação do que precisam aprender (DARLING-HAMMOND et al., 2009; MUSSET, 2010); por outro, e em maior número, está a crença de que as escolas são lugares valiosos para a aprendizagem dos professores, pois permitem o protagonismo e a interação entre eles [...] rompendo com o isolamento do professor na sala de aula e propiciando o aprendizado sobre a prática (DARLINGHAMMOND et al., 2009; VAILLANT, 2016).

O que se observou nas ações de formação continuada promovidas nas escolas municipal lócus dessa observação, é que a equipe técnico-pedagógica, embora as tenha desenvolvido, no período de 2017 a 2019, com o objetivo principal de discutir temas e assuntos relacionados aos vários aspectos do trabalho pedagógico e da organização da instituição escolar, tem incentivado os professores a participarem de eventos e apresentarem trabalhos em congressos e seminários promovidos pelas universidades. Desse modo, muitos professores da referida escola têm ingressado em cursos de mestrado em educação, visando aperfeiçoar a sua formação acadêmica.

A diretora da escola, após concluir o mestrado profissional em educação, criou o Grupo de Estudo "Alfabetização em Foco" em parceria com a Universidade Estadual de Mato Grosso do Sul (UEMS). Esse grupo realiza encontros quinzenais com a participação de professores da própria escola e de outras localizadas em regiões próximas. Os encontros contam com a participação de professores doutores da Universidade Estadual de Mato Grosso do Sul (UEMS) e de outras universidades de Campo Grande-MS. Algumas palestras são realizadas por professores da própria escola, que cursaram o mestrado, desenvolvem e publicam pesquisas na área da educação. O Grupo de Estudo tem priorizado a discussão de temas relacionados à alfabetização, à organização do trabalho didático, à formação dos profissionais da educação, ao currículo da educação infantil e do ensino fundamental, à aplicação de recursos 
tecnológicos no trabalho docente e nas atividades dos alunos, à participação das famílias nas atividades da escola e no processo educacional dos filhos, entre outros.

Nóvoa (2012), ao discutir sobre a formação de professores, apresenta uma síntese que expressa com clareza os "novos modelos de organização das instituições e dos programas de formação" que permeiam as pesquisas a respeito dessa questão, e que têm ocupado grande espaço nas produções acadêmicas sobre a educação, desde anos de 1990: professores para dentro da profissão, isto é, dar aos professores um maior peso na formação dos seus futuros colegas e dos seus pares.

2 - Valorizar o conhecimento profissional docente, um conhecimento elaborado a partir de uma reflexão sobre a prática e sobre a experiência,

transformando-o num elemento central da formação.

3 - Reconstruir o espaço acadêmico da formação de professores, num quadro de reforço das redes de colaboração e de cooperação, criando novas instituições que juntem a realidade das escolas e a realidade das escolas de formação (universidades). 4 - Articular a formação de professores com o debate sociopolítico,

desenvolvendo iniciativas no sentido da definição de um novo contrato social em torno da educação (NÓVOA, 2012, p.20).

O desenvolvimento da formação continuada, conforme $\mathrm{o}$ debate sobre essa temática na atualidade pode utilizar diferentes estratégias. Pode, por exemplo, ser efetivada pelos profissionais técnico-pedagógicos da escola no formato presencial ou no formato à distância. Atualmente, a formação continuada na modalidade à distância tem sido muito fortemente indicada pelas políticas educacionais gerenciadas pelo Estado. O Ministério da Educação e as Secretarias de Educação dos Estados e dos Municípios têm disponibilizado plataformas que possibilitam discussões, estudos e acesso a materiais que tratam de assuntos relacionados à educação em geral e ao trabalho do professor em especial. Existem, também, muitas plataformas construídas por institutos e fundações $^{10}$ do setor privado que têm a finalidade de realizar a formação continuada de professores na modalidade à distância. Essas empresas privadas têm estabelecido parceria com as Secretarias de Educação dos Estados e dos Municípios, no sentido de disponibilizar os seus produtos voltados para a organização da escola pública, dentre eles, encontra-se uma proposta de formação continuada de professores da educação básica. Esse fato, contudo, na concepção de Magalhães e Azevedo (2015, p. 17), pode dar à formação continuada dos docentes uma "perspectiva mercadológica", “[...] enaltecendo modelos, na medida em que pressupõe o professor como executor, responsável pelo preparo de alunos para o mercado de trabalho $[. . .]^{\prime \prime}$.

Com base no exposto, aqui, a questão da formação continuada, ao longo da sua conformação de política pública expressa nas normas legais, nos projetos e programas instituídos pelo Ministério da Educação, e nos estudos empreendidos pelos pesquisadores da academia, precisa ser analisada sob o contexto dos determinantes sociais que envolvem as funções históricas da escola na contemporaneidade. As formações dos profissionais da educação precisam considerar as necessidades concretas de educação mediante o movimento da sociedade, no sentido de promover o debate crítico de propostas que visam simplesmente à preparação dos estudantes para desempenhar funções que atendam as demandas do mercado. Conforme os estudos Alves (2008, p. 109), "[...] um tecnicismo estreito e rudimentar, centrado no 'como ensinar', ainda dominante nos cursos de formação e treinamento de professores, deve ceder espaço ao próprio domínio do conhecimento". Ou seja, é necessário propiciar ao professor, ao longo da sua formação profissional, "além dos saberes técnicos, o acesso ao conhecimento culturalmente significativo encontrado nos livros

\footnotetext{
${ }^{10}$ Podem ser citados os seguintes: Instituto UNIBANCO, Instituto Ayrton Senna; Fundação Lemann.
} 
e nos textos clássicos, como uma forma de instrumentalizar os docentes para buscarem uma nova forma de organização do trabalho didático" (ALVES, 2006, p. 251).

\section{CONCLUSÕES}

Este artigo procurou desenvolver um estudo sobre a formação continuada, tendo como suporte a experiência observada em uma Escola Municipal de Campo Grande-MS, no período de 2017 a 2019, destinada a professores da educação infantil e ensino fundamental.

A escola, ao realizar a formação continuada de professores, teve como princípio fundamental o trabalho coletivo, que procurou envolver a coordenação pedagógica, a direção escolar e o grupo de professores. Para efetivar esse trabalho coletivo foram utilizados vários instrumentos como: Cronograma Anual de Formação de Professores, Fichas de Organização da Reunião Pedagógica, Atas, Ficha de Avaliação dos Encontros de Formação e Plataforma Moodle.

A formação continuada foi executada pela instituição escolar por meio de encontros que ocorrem na própria escola. Esses encontros eram destinados para discussões de assuntos voltados à gestão escolar, à organização da escola, às atribuições de cada profissional, como também para a ampliação de estudos sobre temáticas relacionadas à educação básica. Durante os encontros foram utilizadas diversas metodologias com o propósito de intensificar a participação de todos os profissionais, pois a escola tinha como um de seus objetivos principais favorecer o diálogo entre os professores, os coordenadores pedagógicos e a direção escolar.

A existência, na Escola Municipal de Campo Grande-MS onde se realizou a observação, de um Grupo de Estudo que reúne profissionais com a finalidade de aprofundar estudos e pesquisas sobre a educação merece destaque, haja vista que não é frequente encontrar, no âmbito das escolas públicas, a realização sistemática do estudo por meio de grupos de professores que buscam a parceria com as instituições de ensino superior. A relevância da participação das universidades brasileiras na formação continuada dos professores fica evidente nas pesquisas feitas pela maioria dos autores que discutem esse tema.

Entende-se que a formação continuada de professores tem sido preconizada em documentos, legislações e produções de muitos autores a partir da década de 1990. Os documentos e as normas legais, nesse período, ampliam a normatização de vários aspectos relacionados à formação dos profissionais da educação. Os autores, de um modo geral, têm considerado que a formação continuada é fundamental no processo de construção de conhecimento do professor, visando ao aperfeiçoamento da organização do trabalho didático.

$\mathrm{Na}$ abordagem sobre formação continuada deste estudo, partiu-se do pressuposto de que ela deve ser compreendida a partir do contexto histórico em que a escola está inserida, tendo em vista o fato de que a instituição escolar recebe influências de ordem econômica e política. Contudo, entende-se que as atividades de formação continuada desenvolvidas pela escola não resolvem todas as mazelas da sociedade contemporânea. É preciso ressaltar que a escola pública, na atualidade, exerce diversas funções no sentido de atender demandas próprias de uma época histórica. Diretores e coordenadores pedagógicos da escola, ao promoverem uma formação continuada efetiva aos professores, devem levar em conta que as relações postas pela sociedade influenciam na organização do trabalho didático (ALVES, 2006).

Pretende-se que este estudo represente de alguma forma, um subsídio à abordagem acerca da formação continuada, uma base para estudos futuros sobre o tema e, para a escola municipal em referência, um suporte para reflexões concernentes às ações que tem desenvolvido nessa área.

\section{AGRADECIMENTOS}

Agradecemos à Escola Municipal de Campo Grande-MS que foi o lócus de observação, pela oportunidade de vivenciar uma experiência de formação continuada e, consequentemente, estudá-la à luz de fontes documentais e de produções teóricas.

Os autores declaram não haver qualquer potencial conflito de interesse que possa interferir na imparcialidade deste trabalho científico.

\section{REFERÊNCIAS}

ALVES, G. L. A produção da escola pública contemporânea. Campo Grande, MS: ED. UFMS; Campinas, SP: Autores Associados, 2006. 
ALVES, G. L. O trabalho didático na escola moderna: formas históricas. Campinas, SP: Autores Associados, 2005.

ALVES, G. L. Formação de professores: uma necessidade de nosso tempo?. Revista HISTEDBR On-line, Campinas, n. 31, p. 102-112, Set. 2008. Disponível em: https://periodicos.sbu.unicamp.br/ojs/index.php /histedbr/article/view/8653190/22299. Acesso em: 15 ago. 2020.

BRASIL. Presidência da República. Lei de Diretrizes e Bases da Educação Nacional № 9.394, de 24 de dezembro de 1996. Brasília, 2017. Disponível em: http://www.planalto.gov.br/ccivil 03/leis/19394. $\underline{\mathrm{htm}}$. Acesso em: 11 ago. 2020

BRASIL. Plano Nacional de educação: PNE 20142024. In: SAVIANI, D. Suplemento ao livro Sistema Nacional de Educação e Plano Nacional de Educação: significado, controvérsias e perspectivas. Campinas, SP: Autores Associados, 2014.

BRASIL. Ministério da Educação. Diretrizes Curriculares Nacionais Gerais da Educação Básica. Brasília: MEC, SEB, DICEI, 2013. Disponível em: http://portal.mec.gov.br/docman/julho2013-pdf/13677-diretrizes-educacao-basica2013-pdf/file. Acesso em: 31 jul. 2020

CAMPO GRANDE. Escola Municipal de Campo Grande-MS. Projeto Político Pedagógico, 2016. Disponível na Biblioteca da Escola em formato impresso.

CAMPO GRANDE. Escola Municipal de Campo Grande-MS. Regimento Escolar. Aprovado pela Ata no 04, de 05 de julho de 2019. Disponível na Biblioteca da Escola em formato impresso.

CAMPO GRANDE. Secretaria Municipal de Educação. Resolução no 200, de 21 de novembro de 2019. Diário Oficial de Campo Grande, de 25 de novembro de 2019, p. 17-18. Disponível em: http://portal.capital.ms.gov.br/diogrande/diario Oficial. Acesso em: 25 mar. 2020.

CUNHA, A. M. de O.; KRASILCHIK, M. A Formação Continuada de Professores de Ciências: percepções a partir de uma experiência. In: XXIII
REUNIÃO ANUAL DA ANPED, 23, 2000. Anais... Caxambú, 2000.

HENGEMÜHLE, A. Gestão de ensino e práticas pedagógicas. Petrópolis, RJ: Vozes, 2007.

MAGALHÃES, L. K.C. de; AZEVEDO, L. C. S. S. Formação continuada e suas implicações: ente a lei e o trabalho docente. Caderno Cedes. Campinas-SP, v. 35 , n. 95 , p. $15-26$, jan./abr. 2015. https://doi.org/10.1590/CC0101$\underline{32622015146769}$

MORICONI, G. M. (Coord.). Formação Continuada de Professores: contribuições da literatura baseada em evidências - Relatório de Pesquisa. São Paulo: Fundação Carlos Chagas, 2017.

NÓVOA, A. Devolver a formação de professores aos professores. Cadernos de Pesquisa em Educação, Vitória-ES, ano 9, v. 18. n. 35, p. 11-22, jan/jun. 2012.

REBOLO, F.; TEIXEIRA, L. R. M.; PERRELI, M. A. de S. (Orgs.). Docência em questão: discutindo trabalho e formação. Campinas, SP: Mercado de Letras, 2012.

ROSA, M. I. F. P. dos S.; SCHNETZLER, R. P. A investigação-ação na formação continuada de professores de Ciências. Ciência \& Educação, Bauru, v. 9, n. 1, p. 27-39, 2003. https://doi.org/10.1590/S1516-

\section{3}

SILVA, A. T. T.; VARGAS, I. A. de. Formação de professores de geografia no âmbito da escola pública de Campo Grande (MS). In: CATAMANTE, B. R.; PAIXÃO, R. O.; SILVA, W. G. da. Saberes e fazeres educacionais: reflexões e experiências em torno da formação de professores, diversidade e organização do trabalho didático. Dourados, MS: Seriema, 2016, p. 165-185.

TEIXEIRA, L. R. M. A formação docente: as narrativas autobiográficas como recurso para um enfoque clínico. In: REBOLO, F.; TEIXEIRA, L. R. M.; PERRELI. M. A. de S. (Org.). Docência em questão: discutindo trabalho e formação. Campinas, SP. Mercado de Letras, 2012, p. 109134. 